\title{
O IMPACTO DA INTERNET NO FUNCIONAMENTO DAS INSTITUIÇÕES REPRESENTATIVAS: O CASO DO PARANÁ.
}

\author{
Andressa Silvério Terra França ${ }^{1}$ \\ Fernando Rafael Santos Martins ${ }^{2}$ \\ Sérgio Soares Braga ${ }^{3}$
}

\begin{abstract}
RESUMO
Procuraremos nesse artigo fazer um balanço de algumas das principais teses existentes na literatura sobre as relações entre Internet e política e, a partir do exame critico de tais teses, abordar problemas referentes ao impacto da Internet no funcionamento da democracia representativa, bem como relativos ao uso que os políticos e instituições políticas do Paraná fazem dessa ferramenta para divulgar suas atividades e interagir com o cidadão comum. Palavras-chave: Internet e politica; democracia representativa; interação entre representante e eleitor; parlamentares paranaenses.

\section{THE IMPACT OF INTERNET ON REPRESENTATIVE INSTITUTIONS: THE CASE OF PARANÁ STATE}

\begin{abstract}
The aim of this article is to make a balance of some of the main thesis existing in literature about the relations between Internet and politics and to analyze a "survey" applied for 158 parliamentarians of the state of Paraná about this subject.
\end{abstract}

Keywords: Internet and politics; representative democracy; accountability; parliamentarians and public opinion

\section{Introdução}

Em sua edição de 2 de abril de 2006, o jornal The New York Times publicou longo artigo $3 / 4$ amplamente reproduzido em sites e portais de notícias brasileiros $3 / 4$ onde se afirma que, cada vez mais, a Internet tende a se constituir numa importante ferramenta de contato e interação dos políticos

\footnotetext{
1 Mestranda em Sociologia, DECISO/UFPR

2 Jornalista e pós-graduado em sociologia política/UFPR

3 Professor de Ciência Politica, DECISO/UFPR
} 
norte-americanos com seus eleitores. Segundo o prestigioso jornal, o uso sistemático das Novas Tecnologias de Informação e Comunicação (doravante referido como TICs) tende a produzir amplas mudanças em múltiplos aspectos da atividade política, tais como a forma como são organizadas as campanhas e a propaganda políticas, o tipo de interação entre candidato e opinião pública, a maneira como são formadas as preferências pelo eleitor, e até mesmo a forma de financiamento das campanhas eleitorais ${ }^{4}$.

Observadores e especialistas consultados pelo jornal prevêem um efeito avassalador da Internet no próximos pleitos estadunidenses, especialmente nas eleições para o Congresso em 2006 e para a presidência da República em 2008 , com o uso de novas mídias tais como web sites pessoais, listas de e-mails e blogs de políticos, substituindo progressivamente, com cada vez mais eficácia, antigas formas de organização das campanhas eleitorais, fundadas basicamente no contato físico do parlamentar com o eleitor e no uso de mídias tradicionais, tais como a televisão, publicações impressas e assim sucessivamente.

Não é necessário, entretanto, consultar o The New York Times para darse conta desse fato. A Internet invade cada vez mais o quotidiano do cidadão comum e qualquer observador minimamente informado e sensivel aos acontecimentos do mundo que o cerca pode verificar, por si mesmo, inúmeros exemplos do impacto da Internet sobre a vida social quotidiana. Naturalmente, a atividade política e as instituições da democracia representativa não poderiam ficar imunes a tais efeitos e, mais cedo ou mais tarde, teriam também que sofrer os influxos das TICs.

O objetivo deste artigo é abordar algumas destas questões referentes ao uso da Internet pelos parlamentares e instituições representativas no processo político contemporâneo, tomando como base de análise o estado do Paraná e um pequeno survey que aplicamos aos políticos paranaenses. $\mathrm{O}$ universo empírico do artigo será a pesquisa que empreendemos sobre o uso que os 158 parlamentares paranaenses atualmente no exercício do mandado ( 3 senadores; 30 deputados federais; 54 deputados estaduais; 34 vereadores de Curitiba; 18 vereadores de Londrina e 15 vereadores de Maringá) fazem da Internet para divulgar suas atividades e interagir com o cidadão comum e com o eventual eleitor.

Para abordar estes problemas, dividiremos o texto em três partes: 1) Inicialmente, faremos um balanço de algumas das principais teses existentes na literatura sobre as relações entre Internet e política, especialmente sobre os efeitos que o uso das (TICs) têm produzido nos sistemas politicos demo-

\footnotetext{
${ }^{4}$ NAGOURNEY, A. Politics faces sweeping change via the Web. The New York Times, New York, 02 apr. 2006. p. Disponivel em: http://www.nytimes.com/2006/04/02/.
} 
cráticos contemporâneos; 2) em seguida, abordaremos brevemente alguns aspectos jurídicos referentes ao uso que os candidatos a cargos eletivos, e também os políticos atualmente no exercício do mandato, podem fazer da Internet para divulgar seus trabalhos e suas propostas políticas; 3) por fim, examinaremos algumas evidências empíricas da pesquisa por nós realizada nos sites dos Legislativos brasileiros, bem como do uso que os políticos paranaenses atualmente no exercício do mandato fazem da Internet para divulgar suas atividades e interagir com a opinião pública. Para tanto, analisamos os web sites e enviamos questionários a 158 parlamentares do estado do Paraná, visando a avaliar os potenciais da Internet enquanto recurso eficaz para o aperfeiçoamento de nossas instituições representativas.

\section{1) Internet, política e democracia: alguns balizamentos analíticos}

Como observamos acima, é mais ou menos evidente que a Internet, ao abrir canais de comunicação mais práticos e econômicos, tem modificado a forma como as pessoas se relacionam socialmente. A Política, como parte integrante do conjunto de relações sociais, também sofre influência destas novas tecnologias.

Com efeito, diversos autores têm procurado analisar os impactos que a web provoca e pode provocar sobre a democracia contemporânea. Alguns chegam a vislumbrar a emergência, por meio da Internet, de uma nova modalidade de democracia, a "democracia direta eletrônica", sistema no qual os cidadãos se encontrariam em um ambiente virtual de deliberação sobre os temas de interesse comum: a Ágora Virtual. ${ }^{5}$

Outros estudiosos, mais realistas, reconhecem que a Internet tem um grande potencial democratizante, mas sem chegar aos extremos de instaurar uma "democracia deliberativa direta" ou "democracia deliberativa" nas sociedades contemporâneas, e nem residiria aí necessariamente sua principal contribuição ao aperfeiçoamento do processo político. As TICs podem, de fato, aproximar elites dirigentes e cidadãos comuns, mas tal fenômeno ocorrerá dentro dos quadros do modelo democrático representativo parlamentar. Entretanto, como observado por analistas recentes como Sorj ${ }^{6}$, ainda são escassos estudos empiricamente orientados que busquem

\footnotetext{
${ }^{5}$ Lembrando que a Ágora era a praça onde os cidadãos da Grécia Clássica se reuniam para decidir sobre os temas de interesse da comunidade e considerada por muitos teóricos da democracia como o simbolo da democracia direta grega.

${ }^{6}$ Cf. SORJ, B. "Internet, Espacio Publico y Marketing Politico: Entre la promoción de la comunicación y el solipsismo moralista". Centro Edelstein de Investigaciones Sociales, Working Paper 2, Rio de Janeiro, 2006, p.5. Disponivel em: 〈http://www.centroedelstein.org.br/espanol/working.shtml >. Acesso em 6 maio 2006.
} 
mensurar de forma mais fundamentada os reais impactos do uso da Internet no processo de tomada de decisões, de uma maneira geral, e no processo eleitoral, em particular.

Dada a diversidade de posições na literatura sobre o assunto, convém iniciar este texto com um mapeamento das principais posições existentes na bibliografia sobre a temática.

\section{1) A Internet, a "Ágora virtual" e a "democracia deliberativa"}

Um amplo conjunto de pesquisadores vêem nas TICs a possibilidade de emergência de uma "democracia direta eletrônica" ou de uma "democracia deliberativa", na qual todos ou pelo menos a maior parte dos cidadãos poderiam usar a Internet para deliberar sobre os temas públicos. Tal abordagem é influenciada, direta ou indiretamente, por uma corrente de pensamento inspirada na obra do filósofo alemão Jürgen Habermas, que preconiza a necessidade de as decisões políticas serem tomadas a partir de discussões com ampla participação, em detrimento do modelo de democracia representativa tradicional.

Celso Candido ${ }^{7}$, por exemplo, afirma que os recursos de comunicação proporcionados pela Internet permitirão a criação de um espaço público deliberativo eletrônico: a "Ágora Virtual", onde todos os cidadãos poderão se encontrar virtualmente para deliberar a respeito de assuntos públicos. Para este autor, a Internet levará à emergência de uma nova forma de democracia direta, preferivel à atual democracia representativa. Os meios eletrônicos de comunicação libertariam a democracia da necessidade da representação 3/4 uma exigência imposta pela extensão territorial dos Estados Modernos e pela impossibilidade de haver uma assembléia de todos os cidadãos em um mesmo espaço físico.

Fishkin ${ }^{8}$, de modo semelhante a Candido, também acredita que as TICs podem reconfigurar a democracia por meio da ampliação de canais deliberativos. $\mathrm{O}$ autor chega inclusive a conceber um mecanismo ideal ao qual dá o nome de "Dia da Deliberação": data na qual todos os cidadãos de uma nação participariam de discussões on-line para deliberar sobre um determinado assunto. Para Fishkin, o "Dia da Deliberação" poderia promover o

\footnotetext{
${ }^{7}$ Cf. CANDIDO, C. "A Construção da Ágora Virtual". Monografia vencedora do Prêmio Florestan Fernandes Dez Dias na Grécia - "A construção da democracia", categoria pós-graduação, promovido pela Universidade de Brasília e União Nacional dos Estudantes. Porto Alegre, 1997. Disponivel em: 〈http://caosmose.net/candido/unisinos/af/agoravirtual.htm〉. Acesso em: abril de 2006.

${ }^{8}$ Cf. FISHKIN, J. S. Possibilidades Democráticas Virtuais: perspectivas da democracia via Internet. In: Eisenberg, J.; Cepik, M. (Orgs.). Internet e Política: teoria e prática da democracia eletrônica. Belo Horizonte: UFMG, 2002. p. 17-45.
} 
máximo de participação pública e o maior refinamento possivel da decisão (por permitir uma ampla e esclarecida discussão).

Também podemos destacar o enfoque de Eisenberg ${ }^{9}$, que admite que a Internet produzirá impactos sobre a ação política e que poderá promover a ampliação da democratização nas sociedades contemporâneas, embora ele próprio considere precipitada a visão dos otimistas de que a web criará uma "Ágora Virtual" ou de que será a solução para os problemas da legitimidade da democracia moderna, especialmente de alguns países desenvolvidos, como a apatia eleitoral e o desinteresse de segmentos consideráveis da população em relação à atividade política.

A potencialidade de uma alta capacidade de interação entre receptor e emissor (o que não era possivel ou, ao menos, era muito difícil, por meio das mídias tradicionais, como a televisão, o rádio e a imprensa escrita) propiciada pela Internet, é destacada pelo autor como a principal característica democratizante de tal ferramenta tecnológica, embora o autor também sublinhe a existência de alguns riscos e aspectos negativos no uso da Internet, do ponto de vista da emergência de uma cidadania autenticamente "republicana":

[...] são os mecanismos de interação mediada que a Internet possibilita - listas de discussão e chatrooms - que têm (e podem vir a ter) um impacto mais profundo sobre a política. Por quê? Porque possibilitam a ampliação dos fóruns a públicos de debate e discussão no sentido habermasiano da discussão da ampliação da esfera pública [...] [Entretanto] Como ocorreu com todos os meios de comunicação que antecederam à Internet, o que existe é uma batalha política em curso pela definição dos padrões de apropriação do meio. E ainda não sabemos se será a soberania do consumidor ou a soberania do cidadão que será privilegiada nesse processo. ${ }^{10}$

Outros colaboradores da coletânea organizada por Eisenberg, tais como Guidi" também crêem que "[...] precisamos de redes cívicas e comunidades conectadas, que são a base real da 'teledemocracia' [denominação usada por alguns autores para descrever democracia eletrônica]". ${ }^{12}$ Entretanto a autora, diferentemente dos outros pensadores citados acima, dá um status diferenciado ao e-mail. Para ela, o correio eletrônico constitui-se em um importante

\footnotetext{
"Cf. EISEnBeRG, J. "Internet, Democracia e República". Revista Dados, vol. 46, no 3, Rio de Janeiro, 2003. p. 491-511. Também cf. EISENBERG, J.; CEPIK, M. (Orgs.). Internet e Política: teoria e prática da democracia eletrônica. Belo Horizonte: UFMG, 2002.

${ }^{10}$ EISENBERG, J. "Internet, Democracia e República". Revista Dados, vol. 46, n 3, Rio de Janeiro, 2003. p. 508.

${ }^{11}$ Cf. GUIDI, L. Democracia Eletrônica em Bolonha: a rede Iperbole e a construção de uma comunidade participativa on-line. In: Eisenberg, J.; Cepik, M. (Orgs.). Internet e Política: teoria e prática da democracia eletrônica. Belo Horizonte: UFMG, 2002. p.164-190.

12 Ibid., p.180.
} 
fator para consolidar a participação política da sociedade, observando ainda que o cerne do potencial democratizante dos novos meios de comunicação eletrônicos é a capacidade de interação entre os cidadãos 3/4 característica presente no e-mail.

No entanto, Guidi percebe que atualmente a interatividade na Internet é pouco explorada: "O modelo que prevalece é aquele baseado na 'difusão' (divulgação de informação de um para muitos), através do qual a Internet e seu paradigma de rede vêm sendo subutilizados. A interatividade [...] tem neste modelo um papel muito limitado em relação ao papel do meio". ${ }^{13}$ Como conseqüência, observa a autora, as experiências de participação eletrônica dos cidadãos no processo de tomada de decisões políticas ainda são raras ao redor do mundo.

\section{2) Em direção a uma avaliação realista e empiricamente fundamenta- da dos impactos da Internet sobre a democracia representativa.}

Para os fins deste estudo, destacamos as contribuições da cientista politica de Harvard, Pippa Norris ${ }^{14}$. A autora rejeita a idéia tanto de autores "cyberotimistas", segundo os quais a Internet levará a uma democracia direta virtual ou "deliberativa", como dos "cyberpessimistas", que crêem que nada será mudado com a emergência da web, baseados no argumento de que as TICs apenas irão reforçar os padrões de comunicação (e de poder) existentes atualmente.

A autora desenvolve o argumento de que há duas principais influências da Internet sobre as democracias: ampliar os canais de informação pública acessíveis à população e dinamizar a comunicação da sociedade com as instituições políticas representativas. Cidadãos e grupos de interesse podẹrão participar mais ativamente do processo político em virtude das facilidades de comunicação, partidos políticos terão à frente novas condições para a competição, a sociedade civil poderá organizar mobilizações de modo mais fácil e a transparência do poder público será ampliada, devido à difusão de informações públicas. Esse processo deve criar um subsistema político virtual que fortaleceria as instituições políticas centrais e os atores políticos intermediários (cidadãos esclarecidos, imprensa, movimentos sociais, grupos de interesse, partidos

\footnotetext{
${ }^{13}$ Ibid., p. 166.

${ }^{14}$ O livro seminal da autora é o seguinte: NORRIS, P. Digital divide; Civic Engagement, Information Poverty, and the Internet Worldwide. Cambridge: Cambridge University Press, 2001.
} 
políticos, etc.), sobretudo nas democracias em processo de consolidação. Tal processo pode ser representado pelo seguinte diagrama ${ }^{15}$ :

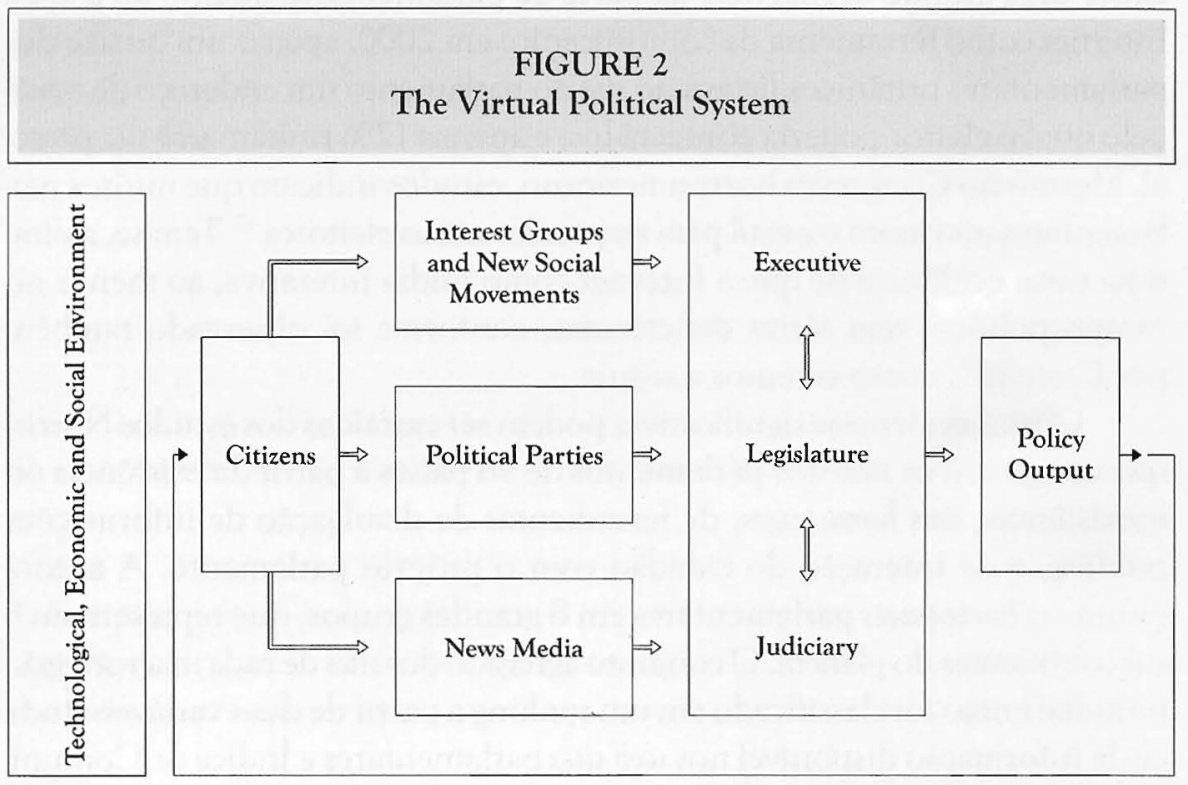

Para o presente texto, interessam em particular os argumentos de Norris à respeito dos impactos da Internet sobre a democracia no que diz respeito à ampliação da comunicação entre a sociedade e o poder público. "A comunicação é essencial para que os representantes eleitos reflitam a visão de seus eleitores e dediquem-se, em nome deles, a suas queixas administrativas particulares". ${ }^{16}$ Nesse sentido, a Internet pode promover uma interação maior entre o cidadão e o político e, conseqüentemente, uma maior representação dos anseios da sociedade no processo decisório. No entanto, deve-se ressaltar, o e-mail não substituirá os outros meios de comunicação e de interação já existentes, embora apresente vantagens em relação a eles. O correio eletrônico apenas se somará às formas tradicionais de comunicação.

É necessário ainda ilustrar com evidências empíricas a influência que a Internet pode efetivamente vir a desempenhar na criação de novas possibilidades de interação entre sociedade e os representantes eleitos, para evitar

${ }^{15}$ Fonte: NORRIS, P. "Democratic Divide? The impact of the Internet on Parliaments Worldwide". Harvard University, John Kennedy School of Government, 2000. Paper apresentado no Congresso da APSA. Disponivel em: <ksghome.harvard.edu/ .pnorris. shorenstein.ksg/acrobat/ apsa2000demdiv.pdf >. Acesso em 6 maio 2006. 
considerações excessivamente abstratas que se aproximam perigosamente dos textos de ficção cientifica. Dentro dessa perspectiva, Norris demonstra que existe uma grande negligência da parte de parlamentares quanto ao uso da Internet como ferramenta de comunicação: em 2000, apenas um quarto dos parlamentares britânicos listava no site do parlamento um endereço de e-mail pelo qual o eleitor poderia contactá-los; e apenas $12 \%$ tinham web site pessoal. Mesmo no Congresso norte-americano, estudos indicam que muitos parlamentares não usam o e-mail para responder a seus eleitores. ${ }^{17}$ Tem-se, assim, uma nova evidência de que a Internet como mídia interativa, ao menos no campo político, tem sérias deficiências, conforme foi observado também por Castells ${ }^{18}$, como veremos a seguir.

Outras evidências significativas podem ser extraídas dos estudos Norris, que comparou os sites dos parlamentos de 98 países a partir da existência ou inexistência, nas home-pages, de ferramentas de divulgação de informações públicas e de interação do cidadão com o próprio parlamento. A autora reuniu as home-pages parlamentares em 8 grandes grupos, que representam 8 subcontinentes do planeta. $O$ conjunto agregado dos sites de cada macrorregião mundial então foi classificado em um ranking a partir de duas variáveis: Índice de Informação disponível nos web sites parlamentares e Índice de Comunicação (que mede a possibilidade de interação entre o cidadão com o parlamento).

A América do Sul, tanto no indice informacional quando no índice de interatividade, fica com a quarta colocação, atrás, respectivamente, da América do Norte, Europa Ocidental e Escandinávia. ${ }^{19}$ Embora a classificação de Norris não discrimine exatamente qual é a posição do site da Câmara dos Deputados brasileira em relação a outros parlamentos, ela dá indicativos, a partir da classificação da América do Sul, de que o portal na Internet do parlamento nacional pode estar devendo a web sites de outros países mais desenvolvidos no que diz respeito às ferramentas interativas. Na conclusão da autora, existe uma relação direta entre o grau de democratização de um

\footnotetext{
${ }^{16}$ Ibid., p. 6.

${ }^{17}$ CARTER, 1999 apud NORRIS, op. cit., p.11.

${ }^{18}$ Cf. CASTELLS, M. A galáxia Internet: reflexōes sobre a Internet, os negócios e a sociedade. Rio de Janeiro: Zahar, 2003.

19 Os dados de Norris, para o Índice de Informação, são os seguintes: América do Norte (74), Europa Ocidental (69), Escandinávia (53), América do Sul (45), Europa Central e do Leste (38), Ásia Oriental (35), África Subsaariana (36) e Oriente Médio (16). Para o Índice de Comunicação: América do Norte (83), Europa Ocidental (87), Escandinávia (70), América do Sul (69), Ásia Oriental (51), Europa Central e do Leste (47), Oriente Médio (34) e África Subsaariana (33). O valor máximo dos dois indices seria 100 (na hipótese de algum web site ofertar o máximo de informação e de interatividade possivel).
} 
país e a oferta, a partir dos parlamentos, de informação e de mecanismos de participação por meio da web.

Seguindo a linha de investigação aberta por Pippa Norris, Braga ${ }^{20}$ procurou mensurar o "grau de informatização" e a existência de ferramentas de informação e comunicação disponíveis nos sites da Câmara dos Deputados, do Senado Federal e das Assembléias Legislativas dos estados brasileiros, a partir de sete dimensões básicas que estruturam o conteúdo dos sites legislativos: (i) Navegabilidade; (ii) Centros Decisórios; (iii) Dados sobre os Parlamentares; (iv) Processo Decisório; (v) Relação com o Público; (vi) Administração (vii) Comunicação horizontal com órgãos da administração públi$\mathrm{ca} /$ Outros. Para tanto, o autor construiu uma planilha contendo cerca de 180 itens presentes em web sites parlamentares e elaborou uma metodologia de avaliação destes sites. Entretanto, não é o objetivo do autor mensurar a interatividade entre os órgãos legislativos e o cidadão comum.

Cunha, Corrêa e Duclós ${ }^{21}$, porém, deram um passo nesse sentido e procuraram medir o grau de uso das ferramentas eletrônicas de comunicação por políticos brasileiros (no caso, vereadores de municípios com mais 600 mil habitantes). O objetivo não era, porém, mensurar a interatividade do vereador com o cidadão, mas sim do vereador com a prefeitura municipal. A conclusão dos autores é de que praticamente não há comunicação eletrônica (troca de e-mails) entre vereadores e membros do Executivo municipal, embora $87,5 \%$ das Câmaras avaliadas disponibilizassem e-mails aos parlamentares. $^{22}$

A partir desse dado, há indicativos de que, ao menos no nível do Legislativo municipal, o parlamentar faz pouco uso do e-mail. Isso fornece algumas pistas de qual pode ser o comportamento dos políticos brasileiros relação à utilização dessa ferramenta de comunicação (já que grande parte deles inicia a vida política como vereador).

A pesquisa dos autores ainda traz outra importante contribuição para este trabalho: o baixo indice de respostas aos questionários enviados por $e$ mail. Cunha, Corrêa e Duclós, para conseguirem elaborar o trabalho, tiveram que mudar o mecanismo de coleta de informações: do e-mail passou-se a

\footnotetext{
${ }^{20}$ Cf. BRAGA, S. S. "O impacto da Internet no funcionamento dos parlamentos brasileiros: um estudo sobre a informatização dos órgãos legislativos no Brasil". Sociedade Brasileira de Sociologia, Belo Horizonte, 2005. "Paper" publicado nos Anais do XII Congresso da Sociedade Brasileira de Sociologia. Disponivel em: 〈http://www.sbsociologia.com.br〉. Acesso em 2 jul. 2005.

${ }_{21}$ Cf. CUNHA, M. A.; CORREA, S. M.; DUCLÓS, L. C. "Interação entre Executivo e Legislativo apoiada por TI". CATI 2005, São Paulo, 2005. "Paper" apresentado ao Congresso Anual de Tecnologia de Informação.

${ }^{22}$ A conclusão foi extraida a partir da percepção de dirigentes dos núcleos de informática das Câmaras. Não foram ouvidos parlamentares e membros da prefeitura.
} 
utilizar o telefone (com o qual conseguiram resposta de 16 dos 24 municípios selecionados). Desse fato, extrai-se outro importante indicativo para esta pesquisa: o Legislativo (municipal, no caso da pesquisa dos três autores, mas que também poderia ser o federal) não interage de forma adequada com o cidadão que lhe envia mensagens eletrônicas ou, ao menos, com o pesquisador que usa esse meio para fazer seu estudo. Esse indicativo, por sua vez, pode significar duas coisas: o grau de interatividade do Legislativo é baixo e, por consequêencia, a influência do e-mail como instrumento de pressão também o é; e existe o risco de que a taxa de respostas do questionário de nossa pesquisa seja baixo $3 / 4$ fato que acabou sendo verificado também em nossa pesquisa sobre os parlamentares paranaenses.

Por outro lado, estudos recentes têm examinado o impacto da Internet em geral, e do e-mail em particular, em decisões políticas específicas tomadas pelos parlamentares. É o caso, por exemplo, de Martins ${ }^{23}$, que estuda a influência do e-mail sobre as decisões dos parlamentares brasileiros a partir do estudo do caso do projeto de lei da Biossegurança. Baseado em amplo estudo empírico, o autor constata a fraca influência do e-mail na decisão de voto dos parlamentares brasileiros, o baixo grau de interatividade e a negligência de boa parte dos deputados em relação ao uso da Internet. Segundo o autor:

Além da baixa interatividade, os dados da pesquisa ainda comprovam que os deputados, em sua maioria, negligenciam o potencial de difusão de informações pela Internet. Apenas $27 \%$ têm site político pessoal e [...] mesmo aqueles que têm home page própria, de um modo geral não exploram a interatividade que a Internet propicia. ${ }^{24}$

\section{3) Internet, crise de legitimidade e os problemas do "excesso de democracia".}

Dentre os autores que refletiram de maneira mais sistemática e empiricamente fundamentada sobre os impactos da Internet na atividade política, podemos destacar ainda Castells, o qual afirma que as novas formas de comunicação que a Internet proporciona vão afetar profundamente a sociedade e suas práticas (inclusive políticas). Castells, aliás, não se furta de avaliar os atuais impactos da Internet sobre o processo político e sobre o potencial democratizante da web. Como afirma:

\footnotetext{
${ }^{23}$ Cf. MARTINS, F. R. S. A influência do e-mail sobre as decisões dos parlamentares brasileiros: um estudo de caso sobre o projeto de lei da Biossegurança. 2005. 87 f. Monografia (Especialização em Sociologia Politica) - Departamento de Ciências Sociais, UFPR, Curitiba.

${ }^{24}$ MARTINS, op.cit., p. 80.
} 
Esperava-se que a Internet fosse um instrumento ideal para promover a democracia $3 / 4 \mathrm{e}$ ainda se espera. Como dá fácil acesso à informação política, permite aos cidadãos ser quase tão bem informados como seus líderes. Com boa vontade do governo, todos os registros públicos, bem como um amplo espectro de informação não-sigilosa, poderia ser disponibilizado on-line. A interatividade torna possivel aos cidadãos solicitar informação, expressar opiniões e pedir respostas pessoais a seus representantes. Em vez de o governo vigiar as pessoas, as pessoas poderiam estar vigiando o seu governo - o que é um direito delas, já que teoricamente o povo é soberano. Entretanto, a maioria dos estudos e relatórios descreve um quadro melancólico - com a possivel exceção das democracias escandinavas. ${ }^{25}$

O autor reconhece que as redes cívicas virtuais de cidadãos poderão ter um papel social e político crucial. Porém, ele prefere ser cauteloso com relação ao peso que as redes cívicas de cidadãos, que se reuniriam virtualmente para debater e agir politicamente, possam vir a ter no futuro da Internet. As comunidades on-line são em geral efêmeras e as evidências mostram que não há razão para acreditar que a Internet será "uma fonte de comunitarismo renovado". Além disso, as ferramentas propiciadas pela web para a emergência de comunidades ou redes virtuais de cidadãos engajados politicamente (tal como as salas de chat e os fóruns virtuais), no contexto atual da Internet, têm uso apenas secundário, o e-mail, é a principal ferramenta utilizada. ${ }^{26}$

Um dos problemas observados pelo autor é o do subaproveitamento, por parte do Estado e das instituições políticas, do potencial de interatividade proporcionado pela Internet. O poder público usa a web sobretudo "[...] como um quadro de avisos" 27 . Ou seja, a Internet é usada somente para divulgar informações institucionais. Os partidos e os políticos também têm utilizado a Internet para divulgar suas ações, mas ainda preferem as mídias tradicionais (rádio, televisão e jornais) por julgarem estas mídias mais eficazes para a comunicação com o cidadão comum.

Especificamente no caso dos parlamentares, a situação não é diferente, aponta Castells. Os e-mails enviados por cidadãos são negligenciados e práticas tradicionais de fazer política são persistentes, embora o uso da Internet esteja cada vez mais disseminado entre os representantes eleitos.

Outro problema, segundo o autor, é que a sociedade também não tem explorado os potenciais da Internet. $O$ quadro final traçado por CASTELLS é pessimista.

${ }^{25}$ CASTELLS, M. A galáxia Internet. Rio de Janeiro: Zahar, 2003, p.128.

26 ibid., p. 99-100.

${ }^{27}$ Ibid., p. 128. 
Num mundo de crise generalizada de legitimidade política, e de indiferença dos cidadãos por seus representados, poucos se apropriam do canal de comunicação interativo, multidirecional, fornecido pela Internet, de ambos os lados da conexão. Os politicos e suas instituições divulgam suas declarações e respondem burocraticamente $3 / 4$ exceto em época de eleição. Os cidadãos não vêem muito sentido em gastar energia em indagações políticas, exceto quando atingidos por um evento que desperta sua indignação ou afeta seus interesses pessoais. A Internet não pode fornecer um conserto tecnológico para a crise da democracia. ${ }^{28}$

Cairncross $^{29}$ também alerta que a ampliação do potencial de comunicação proporcionada pelo e-mail traz um sério problema para os políticos: a quantidade de mensagens eletrônicas recebidas (na forma de spams ou não) pode ser muito alta e, assim, tornar-se difícil de ser gerenciada. Para o autor, a quantidade de e-mails recebidos pelos políticos também pode levá-los a desvalorizar essa forma de comunicação. Segundo o autor, alguns políticos norte-americanos estimam que $80 \%$ dos e-mails recebidos vêm de cidadãos que não moram no estado ou no distrito que eles representam.

Apesar das limitações da Internet e do e-mail em particular, Cairncross mostra-se otimista quanto à exploração política da web e do correio eletrônico por parte dos cidadãos. Para ela, a revolução das comunicações vai promover um reequilíbrio do poder político entre os cidadãos e o poder público, quase que certamente para melhor. As pessoas poderão comunicar suas opiniões aos dirigentes politicos de uma forma muito mais direta, o que fará com que eles tornem-se mais sensiveis (e talvez mais responsivos) à opinião pública, sobretudo nas democracias estabelecidas. Além disso, os cidadãos poderão se tornar mais bem informados do ponto de vista político por causa das amplas possibilidades de divulgação de informações de interesse público por meio da Internet.

\section{4) A visão da imprensa sobre o impacto da Internet nas instituições democráticas.}

Levantamentos não-acadêmicos, realizados pela imprensa, apontam na mesma direção: a existência de ferramentas eletrônicas de comunicação do cidadão com o poder público não significa necessariamente interatividade entre a sociedade e o Estado. Reportagem realizada pelo jornal Gazeta do

\footnotetext{
${ }^{28}$ Ibid., p.129.

${ }^{29}$ Cf. CAIRNCROSS, F. The death of distance: how the communications revolution will change our lives. Boston: Harvard Business Scholl Press, 1997, p.262.
} 
Povo encaminhou, por e-mail, a 10 órgãos federais brasileiros (incluindo a Câmara dos Deputados e o Senado) pedidos de informações específicas ${ }^{30}$. Apenas dois responderam satisfatoriamente. Seis órgãos não deram resposta (incluindo a Câmara e o Senado). Outros dois apresentaram respostas automáticas mas sem a informação pedida.

Outra avaliação da interatividade dos sites estatais brasileiros foi empreendida pelo jornal Folha de S. Paulo ${ }^{31}$. Foi testado, por meio do envio de e-mails a 112 sites de várias instâncias do poder público ${ }^{32}$, o grau de interatividade dessas home-pages. Não deram nenhuma resposta à mensagem encaminhada pelo jornal 73 sites.

Pela imprensa também se obtiveram as únicas evidências diretas da influência dos e-mails enviados por cidadãos sobre uma decisão parlamentar $3 / 4$ no caso, sobre a proposta de reajuste de $67 \%$ dos salários dos deputados e senadores brasileiros, iniciativa de autoria do então presidente da Câmara, Severino Cavalcanti, apresentada em fevereiro de $2005^{33}$. O projeto, com forte rejeição popular, motivou milhares de cidadãos a enviar mensagens de repúdio aos e-mails dos parlamentares, o que fez com que as caixas de correspondência eletrônicas dos deputados ficassem lotadas. Alguns deputados relataram ter recebido até 800 e-mails por dia criticando a proposta de reajuste salarial ${ }^{34}$. Como se sabe, o projeto acabou sendo arquivado diante da recusa do presidente do Senado, Renan Calheiros, em assinar um ato administrativo que elevaria os salários sem a necessidade de votação em plenário $3 / 4$ já que a proposta já não contava com o apoio dos deputados e senadores em virtude da forte pressão popular.

Obviamente, a profusão de e-mails enviados aos parlamentares contribuiu para o fracasso da proposta de reajuste salarial. Mas não é possível, a partir das informações da imprensa, mensurar o grau exato de influência que as mensagens eletrônicas tiveram sobre a decisão final de arquivamento do projeto. Os e-mails, deve-se ressaltar, foram apenas uma parte da pressão exercida, que ainda se verificou por intermédio de diversas outras fontes:

\footnotetext{
${ }^{30}$ Cf. SANTOS, M. R. dos. Governo do futuro. Gazeta do Povo, Curitiba, 10 abr. 2005. p. 29.

${ }^{31}$ Cf. MISKEVIS, D. Poder on-line. Folha de São Paulo, São Paulo, 17 set. 2003. p. F1, F6, F7.

${ }^{32}$ A Folha de S. Paulo discrimina nominalmente a maioria dos 112 sites avaliados, mas não todos. Não está claro, por exemplo, se o site da Câmara dos Deputados foi avaliado. Dentre as home-pages testadas estão as dos governos estaduais, das Assembléias Legislativas, dos Tribunais de Justiça e das prefeituras das capitais, além de alguns sites do governo federal.

${ }^{33}$ Cf. BRAGON, R.; ZANINI, F. Sem apoio, projeto pode naufragar antes mesmo de chegar à votação. Folha de São Paulo, São Paulo, 2 mar. 2005. p. A4.

${ }^{34}$ Cf. COLON, L. Internautas pressionam e ajudam no fracasso do aumento a deputados. Disponivel em: 〈http://ultimosegundo.ig.com.br〉. Acesso em 12 set. 2005.
} 
governadores e prefeitos, preocupados com as contas estaduais e municipais, editoriais de jornais, artigos na imprensa, mensagens de cidadãos às seções de cartas de leitores de jornais, etc. Assim, deve-se considerar que a proposta de reajuste salarial foi algo que mexeu com a opinião pública de uma forma muito forte e incisiva em um único sentido: o de repudiar o projeto.

Mais recentemente, apareceram em jornais paranaenses artigos abordando o uso da Internet por vários atores políticos no estado do Paraná ${ }^{35}$. Todas estas evidências ilustram que o uso da Internet pelos políticos tende a se constituir num ponto de atenção cada vez maior por parte da opinião pública e de analistas especializados.

\section{5) O uso da Internet nas eleições e campanhas eleitorais.}

Por fim, devemos mencionar a existência de uma bibliografia crescente, especialmente nos EUA, sobre o uso da Internet nas campanhas eleitorais $^{36}$. No Brasil, de nosso conhecimento ainda são poucos os estudos dedicados especificamente a analisar a influência da Internet na organização dos pleitos eleitorais, destacando-se a esse respeito os estudos de Dictson \& Ray ${ }^{37}$ e o recente trabalho de Sorj ${ }^{38}$, sobre os impactos da Internet no referendo sobre o desarmamento, ocorrido em 23 de outubro de 2005. Em relação a esse último texto, seu argumento central é o de que "a expectativa otimista referente ao potencial democratizante das TICs, até agora predominante na bibliografia sobre este assunto, expressa uma projeção especulativa que deve ser confrontada com experiências concretas" 39 . No caso específico do refe-

\footnotetext{
${ }^{35}$ Cf. NEVES, D. Partidos usam pouco a Internet: rede mundial é nova ferramenta de campanha. Gazeta do Povo, Curitiba, 7 mar. 2006, p. 8.; BRAGA, S. S.; FRANÇA, A. S. T. A politica paranaense na Internet. O Estado do Paraná, Curitiba, 9 abr. 2006, p. 7.; BRAGA, S. S.; FRANÇA, A. S. T. Internet, democracia e política. Gazeta do Povo, Curitiba, 30 mar. 2006, p. 14. ${ }^{36}$ Dentre estes, destacam-se os trabalhos de BIMBER, B. A.; DAVID, R. Campaigning on-line: the Internet in U. S. elections. Oxford: Oxford University Press. 2003; CORNFIELD, M. Politics moves online: campaigning and the Internet. EUA: Century Foundation Press, 2004; DAVIS, R. The Web of Politics: The Internet's Impact on the American Political System. Oxford: Oxford University Press, 1999; IRELAND, E.; NASH, P. T. Winning campaigns on-line: strategies for candidates and causes. 2 ed. EUA: Science Writers Pr., 2001; TRIPPI, J. The revolution will not be televised: democracy, the Internet, and the overthrow of everything. New York: Regan Books, 2004; dentre outros.

${ }^{37}$ DICTSON, D.; RAY, D. A moderna revolução democrática; uma pesquisa objetiva sobre eleiçōes via Internet. In: EISENBERG, J.; CEPIK, M. (Orgs.). Internet e Política; teoria e prática da democracia eletrônica. Belo Horizonte: UFMG, 2001. p. 191-232.

${ }^{38}$ Cf. SORJ, B. "Internet, Espacio Publico y Marketing Politico: Entre la promoción de la comunicación y el solipsismo moralista". Centro Edelstein de Investigaciones Sociales, Working Paper 2, Rio de Janeiro, 2006, p.5.

${ }^{39}$ SORJ, B. op. cit., p.1.
} 
rendo sobre o desarmamento, a investigação do autor chega à conclusão de que a Internet foi utilizada de maneira deficiente e desigual pelas diferentes forças em pugna ("Sim" e "Não"), tornando-se um espaço "colonizado por individuos e grupos muitas vezes vinculados ao poder econômico e/ou ao marketing político, que se apropriaram da linguagem da Internet e, sob o manto do anonimato, utilizaram este instrumento sem estabelecer compromissos com os valores cívicos da convivência democrática" ${ }^{40}$, contribuindo assim para o esvaziamento da qualidade do debate público travado sobre a temática.

Entretanto, como não é nossa intenção abordar o tema do impacto da Internet sobre as eleições neste artigo, não dialogaremos com essa literatura aqui, dado que o foco de nosso texto são trabalhos que examinam o papel das TICs no funcionamento dos órgãos parlamentares, especialmente no desempenho das funções de comunicação e informação entre elites dirigentes e o cidadão comum.

\section{2) O uso da Internet pelos políticos paranaenses: evidências empíricas.}

Tendo em vista as considerações anteriores, podemos empreender um breve exame do uso que os órgãos parlamentares e os políticos paranaenses têm feito da Internet. A base empírica deste texto é a pesquisa que empreendemos em 29 sites dos órgãos legislativos (Senado Federal, Câmara dos Deputados e as 27 Assembléias e Câmaras Legislativas) no primeiro semestre de 2005. Além disso, ela abrange a enquete sobre o uso que fazem da Internet 158 parlamentares pesquisados.

\section{1) Os sites legislativos.}

No tocante ao uso que os órgãos legislativos fazem da Internet, em pesquisa que empreendemos no início de 2005, procuramos analisar os sites de 29 órgãos parlamentares brasileiros, nas suas seguintes dimensões relevantes: (i) Navegabilidade (Nav); (ii) Centros Decisórios (CD); (iii) Dados sobre os Parlamentares (Par); (iv) Processo Decisório (PD); (v) Relação com o Público (RP); (vi) Administração (Adm); (vii) Comunicação horizontal com órgãos da administração pública (Outros). Aplicando a metodologia que criamos para mensurar

${ }^{40}$ Ibid., p. 2. 
o "grau de informatização" dos sítios, chegamos aos seguintes resultados, que podem ser sumarizados na seguinte tabela ${ }^{41}$ :

\section{TABELA 1}

Grau de informatização dos legislativos brasileiros (por região e por dimensão)

\begin{tabular}{|l|c|c|c|c|c|c|c|c|}
\hline & Nav & CD & Par & PD & RP & Adm & Outros & $\begin{array}{c}\text { Média } \\
\text { (Região) }\end{array}$ \\
\hline Governo Federal & 90,0 & 93,3 & 76,7 & 97,5 & 74,0 & 66,3 & 77,5 & 82,2 \\
\hline Sudeste & 42,5 & 66,2 & 56,7 & 56,9 & 40,2 & 43,5 & 64,5 & 52,9 \\
\hline Sul & 43,3 & 62,2 & 60,0 & 49,9 & 38,7 & 44,2 & 57,3 & 50,8 \\
\hline Centro-Oeste & 40,0 & 27,2 & 42,9 & 22,5 & 14,5 & 8,8 & 27,5 & 26,2 \\
\hline Nordeste & 29,4 & 26,6 & 34,1 & 22,0 & 11,8 & 8,3 & 40,0 & 24,6 \\
\hline Norte & 27,9 & 20,2 & 33,8 & 21,6 & 7,0 & 7,1 & 18,0 & 19,4 \\
\hline Média (Item) & 45,5 & 49,3 & 50,7 & 45,1 & 31,0 & 29,7 & 47,5 & 42,7 \\
\hline
\end{tabular}

A primeira conclusão substantiva a que chegamos em nossa investigação, é a constatação de uma acentuada desigualdade regional entre os diferentes órgãos legislativos. Enquanto no governo federal (portais da Câmara dos Deputados e do Senado Federal), obtemos uma média de 82,2 pontos, no Norte do país a média obtida pelas sete dimensões analisadas foi de 19,4. Ou seja: analisando os dados em termos agregados, verificamos que há uma acentuada correlação entre a informatização dos órgãos legislativos e o grau de desenvolvimento socioeconômico das diferentes regiões e unidades administrativas brasileiras.

Por outro lado, aplicando a metodologia e analisando os dados obtidos de maneira mais desagregada às várias unidades administrativas, chegamos ainda à seguinte classificação dos sítios legislativos: ${ }^{42}$

\footnotetext{
${ }^{41}$ Fonte: BRAGA, S. S. "O impacto da Internet no funcionamento dos parlamentos brasileiros: um estudo sobre a informatização dos órgãos legislativos no Brasil". Anais do XII Congresso da Sociedade Brasileira de Sociologia, Belo Horizonte, 2005.

${ }^{42}$ Fonte: id. Deve-se sublinhar que a classificação contida no gráfico refere-se à situação no primeiro semestre de 2005. De lá para cá, algumas mudanças já foram feitas, tais como a inauguração dos novos portais da Câmara e do Senado, e de algumas Assembléias Legislativas estaduais, inclusive da ALPR que teve seu novo site inaugurado em maio de 2005.
} 


\section{GRÁFICO 2}

Grau de informatização dos legislativos brasileiros

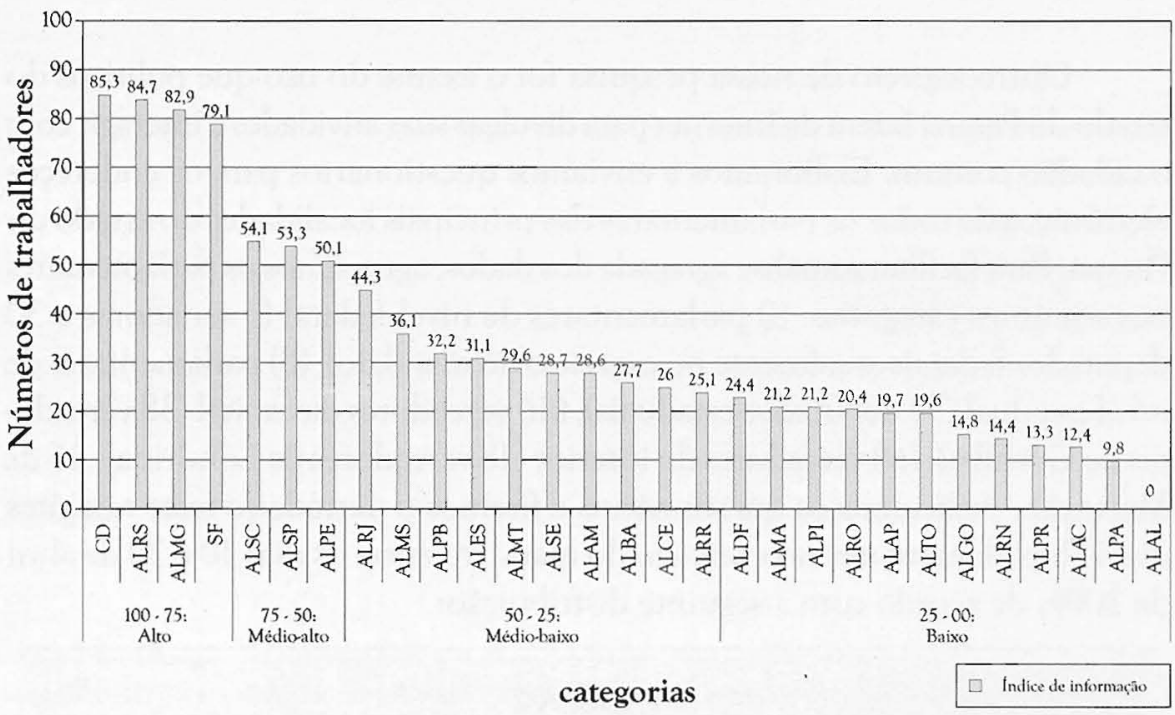

Em termos comparativos, se contrastados com os indices de outros países, os sites de algumas unidades da federação brasileiras alcançaram elevados niveis de informatização ${ }^{43}$. Por outro lado, a principal conclusão do estudo é a de que, de uma maneira geral, os sites legislativos têm sido utilizados basicamente para divulgar informações sobre a atuação dos parlamentares individualmente considerados, restando ainda muito a ser feito no tocante à divulgação de informações sobre aspectos processuais de sua atividade, bem como à dinamização e aperfeiçoamento da interação com o cidadão.

Fazendo uma avaliação global do grau de informatização dos legislativos brasileiros, podemos constatar a existência de quatro grupos bem diferenciados: (i) legislativos com alto grau de informatização, geralmente as unidades administrativas com maior tradição politica e sistemas políticos mais institucionalizados (CD; RS; SF; MG); (ii) unidades com grau médio-alto de informatização (SC; SP; PE); (iii) unidades com grau médio-baixo de informatização; (iv) unidades com baixo grau de informatização. Assim, com exceção de quatro sites que podem ser classificados como possuindo "alto

${ }^{43}$ Em pesquisa que estamos realizando atualmente sobre os sites da América do Sul, verificamos que os sites dos legislativos brasileiros alcançam indices elevados em termos comparativos. Os sites da Câmara dos Deputados e do Senado Federal, por exemplo, estão entre os mais informatizados do mundo, com inúmeros dados sobre o processo legislativo e decisório acessíveis ao cidadão comum. 
grau de informatização", a maioria deles apresenta deficiências de construção e podem ser substancialmente melhorados.

\section{2) Os parlamentares paranaenses e a Internet}

Outro aspecto de nossa pesquisa foi o exame do uso que políticos do estado do Paraná fazem da Internet para divulgar suas atividades e interagir com o cidadão comum. Elaboramos e enviamos questionários para os endereços eletrônicos de todos os parlamentares das principais localidades do estado do Paraná. Para facilitar a análise agregada dos dados, agrupamos os parlamentares nas seguintes categorias: (i) parlamentares de nível federal ( 3 senadores e 30 deputados federais atualmente no exercício do mandato); (ii) parlamentares de nivel estadual (54 deputados estaduais); (iii) vereadores da capital (38 vereadores de Curitiba); (iv) vereadores do interior (18 vereadores de Londrina e 15 de Maringá). Aplicamos os questionários e fizemos o derradeiro teste nos sites dos 158 parlamentares no exercício do mandato entre os dias 10 e 20 de abril de 2006, de acordo com a seguinte distribuição:

\begin{tabular}{|c|c|c|c|c|c|c|c|c|c|c|c|c|}
\hline \multicolumn{13}{|c|}{$\begin{array}{l}\text { TABELA } 2 \\
\text { Parlamentares pesquisados, por partido e categoria }\end{array}$} \\
\hline & \multicolumn{2}{|c|}{ Senador } & \multicolumn{2}{|c|}{$\begin{array}{c}\text { Deputado } \\
\text { Federal }\end{array}$} & \multicolumn{2}{|c|}{$\begin{array}{c}\text { Deputado } \\
\text { Estadual }\end{array}$} & \multicolumn{2}{|c|}{$\begin{array}{l}\text { Vereador } \\
\text { Capital }\end{array}$} & \multicolumn{2}{|c|}{$\begin{array}{l}\text { Vereador } \\
\text { Interior }\end{array}$} & \multicolumn{2}{|c|}{ Total } \\
\hline & $\mathrm{N}$ & $\%$ & $\mathrm{~N}$ & $\%$ & $\mathrm{~N}$ & $\%$ & $r$ & $\%$ & $\mathrm{~N}$ & $\%$ & $\mathrm{~N}$ & $\%$ \\
\hline PMDB & 0 & 0,0 & 8 & 5,1 & 14 & 8, & 3 & 1,9 & 5 & 3,2 & 30 & 19,0 \\
\hline PSDB & 1 & 0,6 & 3 & 1,9 & 9 & 5, & $\varepsilon$ & 5,1 & 3 & 1,9 & 24 & 15,2 \\
\hline PT & 1 & 0,6 & 6 & 3,8 & 9 & 5, & 3 & 1,9 & 5 & $\cdot 3,2$ & 24 & 15,2 \\
\hline PP & 0 & 0,0 & 4 & 2,5 & 2 & 1, & 3 & 1,9 & 5 & 3.2 & 14 & 8,9 \\
\hline PPPPs44 & 0 & 0,0 & 0 & 0,0 & 3 & 1, & 7 & 4,4 & 3 & 1,9 & 13 & 8,2 \\
\hline PPS & 0 & 0,0 & 2 & 1,3 & 5 & 3, & 3 & 1,9 & 2 & 1,3 & 12 & 7,6 \\
\hline PDT & 1 & 0,6 & 0 & 0,0 & 5 & 3, & 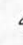 & 2,5 & 1 & 0,6 & 11 & 7,0 \\
\hline PL & 0 & 0,0 & 3 & 1,9 & 1 & 0, & 3 & 1,9 & 4 & 2,5 & 11 & 7,0 \\
\hline PFL & 0 & 0,0 & 2 & 1,3 & 4 & 2 & & 1,9 & 1 & 0,6 & 10 & 6,3 \\
\hline PTB & 0 & 0,0 & 2 & 1,3 & 2 & 1 , & & 0,6 & 3 & 1,9 & 8 & 5,1 \\
\hline Sem partido & 0 & 0,0 & 0 & 0,0 & 0 & 0, & 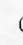 & 0,0 & 1 & 0,6 & 1 & 0,6 \\
\hline Total & 3 & 1,9 & 30 & 19,0 & 5 & 34 & 3 & 24,1 & 33 & 20,9 & 158 & 100,0 \\
\hline
\end{tabular}


A partir da análise dos web sites destes 158 parlamentares e do envio, pelos e-mails disponíveis nos sites institucionais, de questionários a cada um deles, chegamos aos resultados expostos a seguir.

Com relação ao percentual de parlamentares que se utilizam do recurso de web sites pessoais para divulgar suas atividades, temos a seguinte distribuição:

\begin{tabular}{|l|c|c|}
\hline \multicolumn{3}{|c|}{ TABELA 3 } \\
Parlamentares paranaenses com \\
web sites em 20/05/2006 \\
\hline Não têm web site & N & $\%$ \\
\hline Têm web site & 93 & 58,9 \\
\hline Em construção/fora do ar & 6 & 37,3 \\
\hline Total & 158 & 100,0 \\
\hline
\end{tabular}

Temos, assim, um total de 58,9\% dos parlamentares paranaenses sem web sites pessoais para divulgar suas atividades ${ }^{44}$. Embora a maioria dos parlamentares não tenha sites pessoais na Internet, tendo em vista as pesquisas disponíveis em nivel internacional e nacional, o percentual encontra-se ligeiramente acima da média, confirmando a observação efetuada por alguns analistas e admitida pelos próprios parlamentares nas respostas aos questionários que os sites pessoais tendem a se constituir, cada vez mais, num importante recurso tecnológico de divulgação de suas atividades por meio do parlamentares e de acompanhamento, pelos eleitores, do comportamento de seus representantes. Martins ${ }^{45}$, em sua análise da tramitação do Projeto de Lei de Biossegurança, chegou ao resultado de que apenas $27 \%$ dos deputados de sua amostra mantinham sites pessoais, enquanto Norris ${ }^{46}$, analisando o par-

\footnotetext{
${ }^{44}$ Não confundir web sites pessoais com as informaçōes biográficas fornecidas pelos órgãos legislativos em suas home pages. Por "web sites pessoais" entendemos os dominios próprios dos parlamentares na Internet, e não os sites com informações biográficas mantidas pelas diversas instituições parlamentares. Segundo nos informa o site http://www.pagina13pr.org.br/, o custo mensal de manutenção de um site gerenciável com sistema de noticias, informaçōes, publicação de projetos e vários outros itens, é de apenas $\mathrm{R} \$ 35,90$ mensais, a nosso ver teoricamente acessivel aos parlamentares e eventuais candidatos nos vários níveis de governo.

${ }^{45}$ MARTINS, F. R. S. A influência do e-mail sobre as decisões dos parlamentares brasileiros. Curitiba, 2005, p. 80.

46 NORRIS, P. Digital divide. Cambridge, 2001.
} 
lamento inglês e de outros países europeus, obteve o percentual médio de aproximadamente $12 \%$ de parlamentares com web site pessoal.

Devemos observar, entretanto, que o grau de interesse dos parlamentares em divulgar suas informações pela Internet não se distribui igualmente pelos partidos e pelas categorias de parlamentares, conforme podemos verificar pelas tabelas abaixo.

Em relação à distribuição por categorias de parlamentares, ela é a seguinte:

\begin{tabular}{|l|c|c|c|c|c|c|c|c|c|c|c|c|}
\hline \multicolumn{10}{|c|}{ TABELA 4 } \\
\hline & $\begin{array}{l}\text { Deputado } \\
\text { Estadual }\end{array}$ & $\begin{array}{c}\text { Deputado } \\
\text { Federal }\end{array}$ & \multicolumn{1}{c|}{ Senador } & \multicolumn{2}{c|}{$\begin{array}{c}\text { Vereador } \\
\text { Capital }\end{array}$} & \multicolumn{2}{c|}{$\begin{array}{c}\text { Vereador } \\
\text { Interior }\end{array}$} & \multicolumn{2}{c|}{ Total } \\
\cline { 2 - 15 } & $\mathrm{N}$ & $\%$ & $\mathrm{~N}$ & $\%$ & $\mathrm{~N}$ & $\%$ & $\mathrm{~N}$ & $\%$ & $\mathrm{~N}$ & $\%$ & $\mathrm{~N}$ & $\%$ \\
\hline $\begin{array}{l}\text { Fora do ar/em } \\
\text { construção }\end{array}$ & 1 & 1,9 & 1 & 3,3 & 0 & 0,0 & 3 & 7,9 & 1 & 3,0 & 6 & 3,8 \\
\hline Não tem site & 30 & 55,6 & 16 & 53,3 & 0 & 0,0 & 20 & 52,6 & 27 & 81,8 & 93 & 58,9 \\
\hline Tem site & 23 & 42,6 & 13 & 43,3 & 3 & 100,0 & 15 & 39,5 & 5 & 15,2 & 59 & 37,3 \\
\hline Total & 54 & 100,0 & 30 & 100,0 & 3 & 100,0 & 38 & 100,0 & 33 & 100,0 & 158 & 100,0 \\
\hline
\end{tabular}

Todos os três senadores paranaenses possuem sites pessoais, enquanto os índices mais baixos estão entre os vereadores do interior, conforme esperado. Deve-se destacar, entretanto, que o percentual de parlamentares que possuem sites pessoais nos demais níveis de governo é relativamente elevado, oscilando entre um mínimo de $39,5 \%$ (para os vereadores de Curitiba), a um máximo de $43,3 \%$ para os deputados federais. Podemos observar também que não existe correlação estrita entre o "grau de informatização" dos órgãos legislativos nos quais os representantes exercem seu mandato e o percentual de parlamentares que optam por construir sites pessoais. Essa hipótese pode ser comprovada pelo fato de que, entre os 30 deputados federais paranaenses, somente $43,3 \%$ possuem sites pessoais, embora o portal da Câmara dos Deputados apresente o mais elevado índice de informatização de todo o pais.

No tocante aos diferentes partidos políticos, os percentuais são os seguintes: 
TABELA 5

Parlamentares com web sites pessoais, por partido

\begin{tabular}{|c|c|c|c|c|c|c|c|c|c|c|c|c|c|c|c|c|c|c|c|c|c|c|c|c|}
\hline & \multicolumn{2}{|c|}{ PDT } & \multicolumn{2}{|c|}{$\begin{array}{c}\text { Pequenos } \\
\text { Partidos }\end{array}$} & \multicolumn{2}{|c|}{ PFL } & \multicolumn{2}{|c|}{ PL } & \multicolumn{2}{|c|}{ PMDB } & \multicolumn{2}{|c|}{ PP } & \multicolumn{2}{|c|}{ PPS } & \multicolumn{2}{|c|}{ PSDB } & \multicolumn{2}{|c|}{ PT } & \multicolumn{2}{|c|}{ P'TB } & \multicolumn{2}{|c|}{$\begin{array}{c}\text { Sem } \\
\text { Partido }\end{array}$} & \multicolumn{2}{|c|}{ Total } \\
\hline & $\mathrm{N}$ & $\%$ & $\mathrm{~N}$ & $\%$ & $\mathrm{~N}$ & $\%$ & $\mathrm{~N}$ & $\%$ & $\mathrm{~N}$ & $\%$ & $\mathrm{~N}$ & $\%$ & $\mathrm{~N}$ & $\%$ & $\mathrm{~N}$ & $\%$ & $\mathrm{~N}$ & $\%$ & $\mathrm{~N}$ & $\%$ & $\mathrm{~N}$ & $\%$ & $\mathrm{~N}$ & $\%$ \\
\hline & 6 & 54,5 & 6 & 46,2 & 3 & 30,0 & 3 & 27,3 & 9 & 30,0 & 2 & 14,3 & 4 & 33,3 & 6 & 25,0 & 19 & 79,2 & 1 & 12,5 & 0 & $\infty$ & 59 & 37,3 \\
\hline Não tem & 4 & 36.4 & 5 & 38,5 & 7 & 70,0 & 8 & 72,7 & 20 & 66,7 & 11 & 78,6 & 8 & 66,7 & 18 & 75,0 & 4 & 16,7 & 7 & 87,5 & 1 & 100 & 93 & 58. \\
\hline Tem site & 1 & 9,1 & 2 & 15,4 & 0 & 0,0 & 0 & 0,0 & 1 & 3,3 & 1 & 7,1 & 0 & 0,0 & 0 & 0,0 & 1 & 4,2 & 0 & 0,0 & 0 & 0,0 & 6 & 3,8 \\
\hline Total & 111 & 100 & 13 & 100 & 10 & 100 & 11 & 100 & 30 & 100 & 14 & 100 & 12 & 100 & 24 & 100 & 24 & 100 & 8 & 100 & 1 & 100 & 158 & 10 \\
\hline
\end{tabular}

Também aqui se verifica uma acentuada desigualdade na distribuição partidária dos parlamentares que se utilizam do recurso dos web sites pessoais para divulgar suas atividades, com os extremos sendo formados pelo PT (com $79,2 \%$ com sites) e pelo PTB (com $87,5 \%$ dos parlamentares sem web sites pessoais). Até que ponto essas variáveis se correlacionam com outros fatores referentes à organização e ao comportamento dos diferentes partidos políticos, tais como taxa de migração partidária, fidelidade na votação, políticas internas das agremiações e natureza dos vínculos que estabelece com os eleitores e com a militância, é algo que resta por ser investigado.

Podemos agora examinar evidências de outra dimensão importante da relação do parlamentares com a Internet, que é o do grau de interação que os parlamentares possuem com o cidadão comum, tal como mensurado pela taxa de resposta das mensagens enviadas para os endereços eletrônicos que constam nos portais das instituições dos quais cada grupo de parlamentares faz parte.

Lembrando que a pesquisa foi realizada entre os dias 20 de abril e 20 de maio de 2006, e que somente foram aceitas respostas recebidas durante esse periodo. Fizemos quatro tentativas de envio de mensagens individuais a cada parlamentar, no primeiro dia de cada semana, segunda-feira, solicitando resposta para um pequeno questionário de pesquisa, acompanhado de um anexo com informações curriculares nossas.

Findo o período pesquisado, foi a seguinte a taxa de resposta dos parlamentares a nossas mensagens. 


\begin{tabular}{|l|c|c|}
\hline \multicolumn{3}{|c|}{ TABELA 6 } \\
Proporção de resposta \\
dos parlamentares aos e-mail \\
\hline Sem resposta & N & $\%$ \\
\hline Respondeu & 108 & 68,4 \\
\hline Retornou/E-mail desativado & 21 & 13,2 \\
\hline Total & 158 & 100,0 \\
\hline
\end{tabular}

Temos, assim, uma taxa de resposta de apenas $18,4 \%$ que, no entanto, é significativamente superior à taxa verificada durante os cinco meses da pesquisa realizada por Martins ${ }^{47}$. Dessa forma podemos, assim, considerá-la como bastante significativa em termos comparativos, tendo em vista o pouco tempo dado aos parlamentares para responder às mensagens. Como nosso objetivo era testar a velocidade de resposta dos parlamentares, deliberadamente demos pouco tempo para que os mesmos respondessem aos e-mails. Outro dado significativo é o de que $13,2 \%$ das mensagens enviadas retornaram por motivos diversos, tais como e-mail incorretamente informado e lotação de caixa postal. Assim como em relação ao item anterior, também houve um percentual diverso na distribuição entre as diferentes categorias de parlamentares no quesito "interatividade".

\begin{tabular}{|c|c|c|c|c|c|c|c|c|c|c|c|c|}
\hline \multicolumn{13}{|c|}{$\begin{array}{c}\text { TABELA 7 } \\
\text { Parlamentares com sites pessoais, por cargo eletivo }\end{array}$} \\
\hline & \multicolumn{2}{|c|}{$\begin{array}{c}\text { Deputado } \\
\text { Estadual }\end{array}$} & \multicolumn{2}{|c|}{$\begin{array}{c}\text { Deputado } \\
\text { Federal }\end{array}$} & \multicolumn{2}{|c|}{ Senador } & \multicolumn{2}{|c|}{$\begin{array}{l}\text { Vereador } \\
\text { Capital }\end{array}$} & \multicolumn{2}{|c|}{$\begin{array}{l}\text { Vereador } \\
\text { Interior }\end{array}$} & \multicolumn{2}{|c|}{ Total } \\
\hline & $\mathrm{N}$ & $\%$ & $\mathrm{~N}$ & $\%$ & $\mathrm{~N}$ & $\%$ & $\mathrm{~N}$ & $\%$ & $\mathrm{~N}$ & $\%$ & $\mathrm{~N}$ & $\%$ \\
\hline Respondeu & 6 & 11,1 & 7 & 23,3 & 3 & 66,7 & 12 & 31,6 & 1 & 3,0 & 29 & 18,4 \\
\hline Sem resposta & 40 & 74,1 & 19 & 63,3 & 0 & 0,0 & 22 & 57,9 & 27 & 81,8 & 108 & 68,4 \\
\hline $\begin{array}{l}\text { Voltou/E-mail } \\
\text { Inativo }\end{array}$ & 8 & 14,8 & 4 & 13,3 & 0 & 0,0 & 4 & 10,5 & 5 & 15,2 & 21 & 13,3 \\
\hline Total & 54 & 100,0 & 30 & 100,0 & 3 & 100,0 & 38 & 100,0 & 33 & 100,0 & 158 & 100,0 \\
\hline
\end{tabular}

${ }^{47}$ MARTINS, F. R. S. A influência do e-mail sobre as decisões dos parlamentares brasileiros. 2005; CASTELLS, M. A galáxia Internet. 2003. 
Verificamos que os indices mais baixos de resposta aos e-mails ocorreram entre os vereadores do interior $(3,0 \%)$ e os deputados estaduais $(11,1 \%)$. Dos três senadores, todos responderam ao questionário, enquanto que o dado mais significativo refere-se aos vereadores da capital: dos 38 vereadores, 12 responderam às mensagens enviadas, num total de $31,6 \%$, um índice que podemos considerar elevado, tendo em vista os padrões brasileiros e, inclusive, internacionais.

Embora tivessem sido poucos os questionários respondidos (apenas 29 de um total de 158 enviados, num total de $18,4 \%$, percentual não significativo do ponto de vista estatístico), as respostas dos parlamentares nos fornecem alguns dados interessantes.

Solicitados a responder sobre a influência que o e-mail teria em comparação com outros fatores que influenciam as decisões de voto, foi a seguinte a distribuição obtida, de acordo com a seguinte escala: 1) Muita influência; 2) Influência mediana; 3) Pouca influência; 4) Nenhuma influência:

\begin{tabular}{|l|c|c|c|c|}
\hline \multicolumn{5}{|c|}{ TABELA 8} \\
\hline & 1 & 2 & 3 & 4 \\
\hline Os debatores que influencia a decisão de voto \\
\hline A vontade e o posicionamento das bases eleitorais & 60,7 & 35,7 & 3,6 & 6,9 \\
\hline Convicções pessoais & 55,5 & 25,9 & 14,8 & 3,7 \\
\hline Posicionamento do líder da bancada de meu partido & 53,5 & 28,6 & 14,3 & 3,6 \\
\hline Cartas enviadas ao gabinete & 44,8 & 48,3 & 3,4 & 3,4 \\
\hline Mensagens de e-mails enviadas ao endereço eletrônico & 44,8 & 37,9 & 13,8 & 3,4 \\
\hline Posicionamento do chefe do Executivo. & 42,8 & 14,3 & 28,6 & 14,3 \\
\hline Consulta ao site do partido do qual sou filiado & 35,7 & 25,0 & 28,6 & 10,7 \\
\hline Leitura de editoriais de jornais e órgãos da imprensa & 31,0 & 41,4 & 20,7 & 6,9 \\
\hline Leitura de "blogs" da internet & 17,8 & 25,0 & 39,3 & 17,9 \\
\hline
\end{tabular}


Assim, 48,8\% dos respondentes admitiram que as mensagens de e-mail enviadas aos gabinetes tinham influência em sua conduta parlamentar e decisão de voto. Embora outros fatores tais como convicções pessoais, posicionamento do líder do partido e consulta às bases eleitorais, tenham sido mencionados como mais importantes do que o e-mail, este fator supera outros elementos de influência, tais como a consulta ao site do partido, a leitura de órgãos da imprensa, "blogs" da internet e, surpreendentemente, o posicionamento do próprio chefe do Executivo. Logo, embora o e-mail ainda concorra em condição de desvantagem com outros fatores que influenciam com maior intensidade a conduta parlamentar, o percentual de influência do e-mail não possa ser desconsiderado como irrelevante, ao menos para esse percentual de parlamentares que demonstra maior preocupação no emprego da internet para interagir com o eleitor.

Outro dado interessante, que também reforça (além do baixo índice de resposta dos questionários) as teses contidas na literatura sobre a "saturação" que o e-mail pode causar na comunicação entre eleitor e parlamentar, é o elevado número de e-mails diários recebido pelos parlamentares nas instâncias superiores de representação. A totalidade dos senadores (100\%) e metade dos deputados federais recebe mais de 500 e-mails diários em seus endereços eletrônicos, o que dificulta o gerenciamento das informações, conforme já observado em outros estudos sobre o assunto ${ }^{48}$. Por outro lado, nos níveis locais a quantidade de e-mails diários é mais reduzida, o que talvez explique a elevada taxa de resposta dos vereadores de Curitiba obtida durante a pesquisa, além das políticas de estímulo à informatização da casa levadas à cabo pela instituição.

Destaque-se ainda o elevado número de parlamentares que admitiram ter sugerido uma proposição ou projeto de Lei a partir de sugestão encaminhada por e-mail (61,1\%), evidenciando que os parlamentares mais preocupados com a interatividade com o eleitor dão importância ao e-mail também como instrumento de sugestão de proposições.

Por fim, devemos mencionar o alto percentual de respondentes que, embora reconhecendo a importância crescente da Internet no relacionamento com o eleitor $(66,7 \%)$, relutaram em admitir que este recurso vá se desenvolver o suficiente, num horizonte próximo, para substituir formas tradicionais de

\footnotetext{
${ }^{47}$ Durante os cinco meses de sua pesquisa sobre a influência do e-mail nas decisões sobre o PL da Biossegurança, apenas 7 deputados federais de um total de 62 da amostra escolhida por Martins responderam ao questionário, num total de $10,4 \%$ (p. 4). No caso de nossa pesquisa, outros três parlamentares responderam ao questionário após o encerramento do prazo estipulado no e-mail, e por isso não foram computados na tabulação.
} 
relacionamento com as bases eleitorais. Aliás, essa foi a proposição que teve maior proporção de concordância entre os parlamentares, dados que todos eles concordaram, em maior ou menor grau de intensidade, que a Internet, embora esteja adquirindo importância crescente, não é ainda suficiente para substituir o tradicional contato face a face com o eleitor e com as bases eleitorais.

\section{Conclusões}

Podemos, assim, enunciar sinteticamente as principais conclusões deste estudo:

- Contrariando as avaliações iniciais excessivamente otimistas, quase eufóricas, sobre os impactos da Internet no funcionamento dos sistemas políticos democráticos contemporâneos, estudos mais recentes têm apontado vários problemas no uso desse recurso tecnológico (tais como a utilização ainda deficiente, pelos representantes eleitos, de sites pessoais para divulgar suas atividades; a "saturação" do processamento de mensagens enviadas por e-mail; a "monopolização" de listas de debates por indivíduos não comprometidos com os valores cívicos que possibilitem uma adequada convivência democrática), que colocam a necessidade de estudos empíricos mais sistemáticos para avaliar os reais impactos dessa mídia no sistema político.

- No entanto, há um certo consenso na literatura em se observar que consideráveis avanços foram feitos no funcionamento das democracias através do emprego dos recursos tecnológico propiciados pela Internet. $\mathrm{O}$ uso de web sites pessoais bem organizados, por exemplo, pode ser um importante fator de comunicação dos políticos, candidatos e órgãos da administração pública com o cidadão comum e, por outro lado, um eficiente recurso de acompanhamento e fiscalização do poder público por parte da população. Pode também vir a se transformar num importante instrumento de campanha eleitoral, desde que adequadamente utilizado.

- Verificamos uma acentuada desigualdade regional e entre as várias unidades da federação no uso da Internet para divulgar suas atividades. Apenas 4 sites, dentre os 29 analisados, receberam a classificação "alto grau de informatização", indicando que muitos avanços ainda podem ser feitos no tocante a esse aspecto específico. - Uma porcentagem significativa de parlamentares paranaenses já se utilizam de web sites para divulgar suas atividades, porcentagem superior à verificada por estudos anteriores sobre o tema em outros órgãos legislativos, evidenciando que há uma crescente preocupação dos representantes eleitos nos vários niveis de governo em se utilizarem da Internet para divulgar suas atividades para o cidadão comum.

- Entretanto, a interatividade dos representantes eleitos com os cidadãos por intermédio da Internet pode ser considerada insatisfatória. Tal fato deve-se a duas causas: por um lado, a uma certa escassez de recursos humanos especializados no gerenciamento das mensagens enviadas por meio da Internet e, por outro, a uma certa "saturação" dos e-mails como recurso empregado para promover a interação entre eleitor e representante. 